\title{
A rare anatomical variation of the greater saphenous vein. Case report.
}

\author{
Aydın Kurt, Yeliz Aktürk, Baki Hekimoğlu
}

Department of Radiology, Dıskapı Yıldırım Beyazıt Training and Researche Hospital, Ankara, Turkey

\begin{abstract}
The venous system has frequent anatomical variations. A good understanding of the venous anatomy is very important and proper evaluation of the venous system is crucial for the appropriate treatment of venous disorders. There are many variations of the greater saphenous vein at the level of the thigh, knee and leg. All variations of the saphenofemoral junction reported in the literature refer to the drainage of the greater saphenous vein into the common femoral vein. A very rare greater saphenous vein variation at the level of the saphenofemoral junction is defined and discussed in this case report.
\end{abstract}

Keywords: variation, greater saphenous vein, saphenofemoral junction

\section{Introduction}

The venous system has frequent anatomical variations, so it is more variable compared to the arterial system [1]. A good understanding of the venous anatomy is very important and proper evaluation of the venous system is crucial to the appropriate treatment of venous disorders $[1,2]$. Greater saphenous vein (GSV), also known as the vena saphena magna is the longest vein in the body [1-3]. GSV originates from vena marginalis medialis on the medial side of the dorsum of the foot and extends to the leg passing over the malleolus medialis. It extends upwards in the femoral region on the medial side [3-7]. GSV drains into the femoral vein and forms the saphe-

Received 26.09.2013 Accepted 17.11.2013

Med Ultrason

2014, Vol. 16, No 1, 60-62

Corresponding author: Aydın Kurt, MD.

Department of Radiology, Diskap1 Yıldırım Beyazit Training and Researche Hospital.

Irfan Bastug Street, Diskap1,

Postal code: 06120, Ankara, Turkey

Phone: +9003125962000

Mobile: +905323206983

E-mail: yelizakturk@yahoo.com nofemoral junction (SFJ) that is located in the hiatus saphenous [1-7].

There are many variations of the GSV at the level of the thigh, knee and leg. All the variations of the SFJ reported in the literature refer to the drainage of the GSV into the common femoral vein (CFV). In this case report a very rare GSV variation at the level of the SFJ is defined and discussed.

\section{Case report}

A 47-year old female was evaluated for lower extremity venous insufficiency using Doppler ultrasound. The right GSV drained into the superficial femoral vein (SFV) instead of the CVF. There was a short and blind ending vascular structure at the medial aspect of the CFV at the level of the SFJ (fig 1-4). The diameter of the GSV was $6.8 \mathrm{~mm}$ above and $3.3 \mathrm{~mm}$ below the knee and GSV was insufficient in both locations. There were varicose venous structures up to $9 \mathrm{~mm}$ connecting with GSV both below and above the knee. Perforating veins were detected using manual distal compression in the erect position between both the GSV and crural veins in the crural region and small saphenous vein and crural veins 


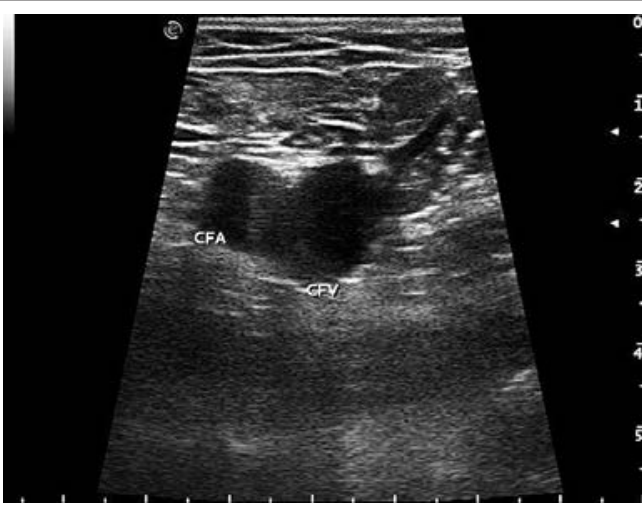

Fig 1. Short axis view at the level of the right femoral triangle. The greater saphenous vein drains into the superficial femoral vein. There is a short and blind ending vascular structure at the medial aspect of the common femoral vein at the level of the saphenofemoral junction. CFA: the common femoral artery; CFV: the common femoral vein.

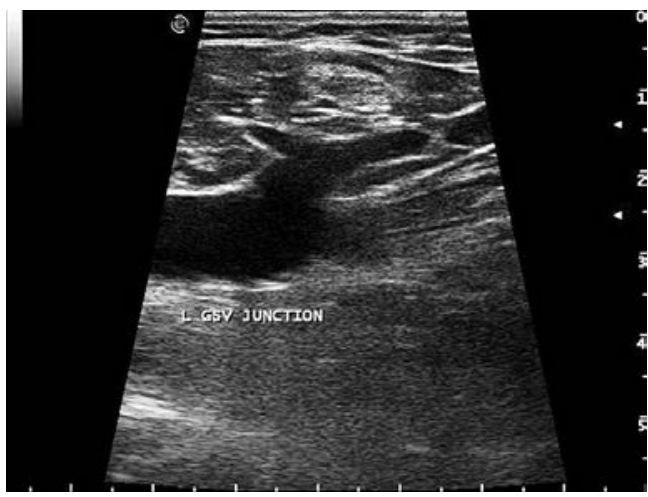

Fig 2. Longitudinal view at the level of the left femoral triangle. The greater saphenous vein drains normally into the common femoral vein. L: left; GSV: the greater saphenous vein.

in the crural region. Saphenopopliteal insufficiency was also detected in the erect position with the manual distal compression.

\section{Discussion}

The GSV is still the most popular vein graft in coronary artery bypass surgery even though synthetic grafts and arteria mammaria interna are becoming used more frequently [3]. It plays an important role in the venous return of the lower extremity because it has a lot of branches along its course and it has relations with deeper veins $[3,4]$. The main tributaries are the superficial epigastric

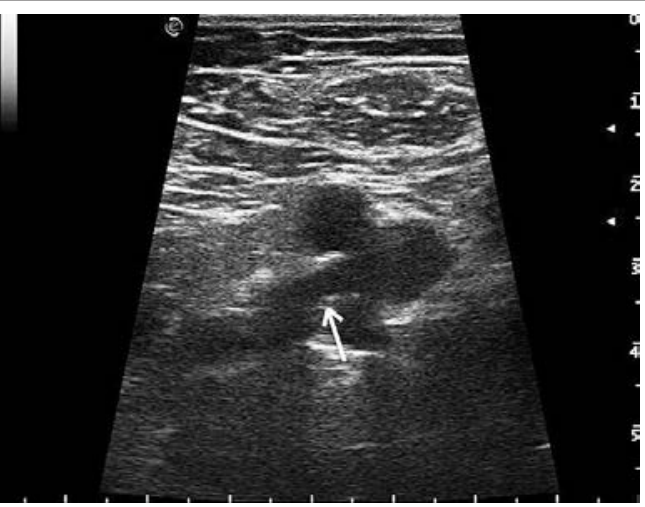

Fig 3. Short axis view at the level of the right femoral triangle. The superficial femoral vein and deep femoral vein unite to form common femoral vein. SFV: the superficial femoral vein; DFV: the deep femoral vein; white arrow: the level of that SFV and DFV unite to form common femoral vein.

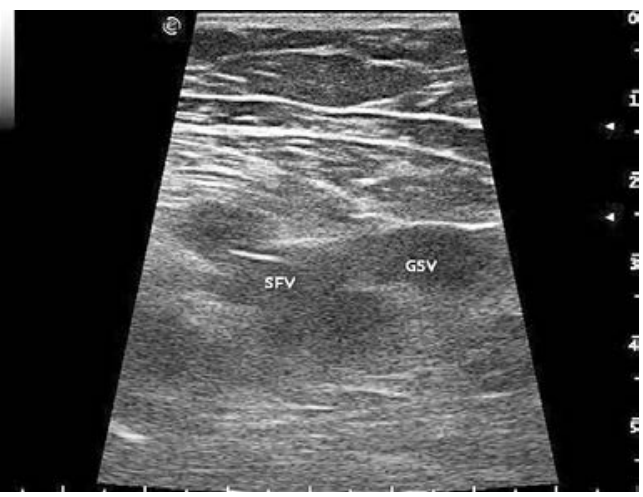

Fig 4. Short axis view at the level of the right femoral triangle. Superficial femoral vein and greater saphenous vein proximal to the common femoral vein. SFV: the superficial femoral vein; GSV: the greater saphenous vein.

vein (SEV), the external pudental vein (EPV), the superficial circumflex iliac vein (SCIV), the medial accessory saphenous vein (MASV) and the lateral accessory saphenous vein (LASV) [8,9]. GSV is not only used in coronary bypass surgery but also in the treatment of cerebrovascular diseases and as grafts in peripheric vascular surgery $[3,10,11]$.

There are many anatomical variations of the GSV at the level of the thigh, calf and knee. Studies of SFJ began at the turn of the 19th century and were dominated by surgeons who stripped the GSV during surgical treatment of varicose veins. In 1916 Homans was the first to ligate all the tributaries of GSV near the SFJ. This mode of op- 
A rare anatomical variation of the greater saphenous vein. Case report.

eration, including many different modifications, remains a principal surgical procedure today [8]. Familiarity with the anatomy of this tributary network, termed by Bruska and Hilty $[8,12]$ the confluens venosus subinguinalis, is therefore very important in the radical surgery of the GSV. The confluens venosus subinguinalis is formed by 5 main veins: GSV, EPV, SEV common truncus, SCIV, and LASV. The connections between them are, however, variable according to Orsini [8,9], who distinguished 135 anatomical variants of the GSV, although without classifying them into general groups as Kocon and Zebrowski's study. Konrad identified 5 types of draining pattern of the GSV according to the number of its direct tributaries. Type 1, with 3 direct collaterals of the GSV, is the most frequently encountered (47.8\%). The common trunk, which drains into the GSV, is formed by the conjunction of 2 or 3 collaterals. It is most often formed by 2 tributaries, SEV and SCIV [8].

In our case GSV did not end in the CFV but drained in to the SFV. To our knowledge, no similar case of SFJ anatomical variation has been defined.

There have been revolutionary developments in the diagnosis and treatment of chronic venous insufficiency in recent years [13]. The treatment options for varicose veins include conservative approach, sclerotherapy, ultrasound-guided sclerotherapy, and junction ligation with or without vein stripping $[13,14]$. Although expertise in venous anatomy and variations may not be necessary in conservative approach, interventional treatment modalities may necessitate expertise. Hence, if important anatomical variations are not recognized, surgical or lesser invasive procedures might result in incomplete SFJ surgery $[13,15]$.

Consequently the knowledge and identification of anatomical variations play an important role in increasing the success and efficacy of surgical treatments and in decreasing the recurrence rates.

\section{References}

1. Chen SS, Prasad SK. Long saphenous vein and its anatomical variations. AJUM 2009; 12: 28-31.

2. Oğuzkurt L. Ultrasonographic anatomy of the lower extremity superficial veins. Diagn Interv Radiol 2012; 18: 423-430.

3. Tuncer I, Büyükmumcu M, Çiçekcibaşı AE, Salbacak A. Vena saphena magna dublikasyonu. Genel Tip Derg 2002; 12: 105-107.

4. Tanyeli E, Yıldırım M, Soyluoğlu İ. Vena saphena magna'nın dökülme yeri ve aksesuar v. saphena magna sıklığı. Morfoloji Derg 2001; 9: 9-11.

5. Çimen A. Anatomi. İstanbul, Nobel 1994; 297-298.

6. Arıncı K, Elhan A. Anatomi. Ankara, Gunes Kitabevi 2013; 100-101.

7. Dere F. Anatomi. 6. bask1. Adana, Nobel 1990; 447-448

8. Janowski K, Topol M. Types of outlet of the major saphenous vein tributaries in patients with chronic vein insufficiency of the lower limbs. Folia Morphol 2004; 63: 473-479.

9. Orsini A, Molfetta S, Pagani C.The importance of anatomical variants of the sapheno-femoral junction in lower limb varicose vein surgery. Minerva Cardioangiol 2001; 49; 257-262.

10. Nair UR, Griffiths G, Lawson RA. Postoperative neuralgia in the leg after saphenous vein coronary artery bypass graft: a prospective study. Thorax 1988; 43: 41-43.

11. Karabulut AK, Üstün ME, Uysal III, Salbacak A. Saphenous vein graft for bypass of the maxillary to supraclinoid internal carotid artery: an anatomical short study. Ann Vasc Surg 2001; 15: 548-552.

12. Bruska M, Wozniak W. Connections between the great saphenous vein and other cutaneus veins of the thigh in human fetuses. Folia Morpol 1996; 55: 222-223.

13. Tavlaşoğlu M, Güler A, Gürbüz HA, Tanrıseven M, Kürklüoğlu M, Yeşil FG. Anatomical variations of saphenofemoral junction encountered during venous surgery. Journal-Cardiovascular Surgery 2013; 1: 5-7.

14. Leopardi D, Hoggan BL, Fitridge RA, Woodruff PW, Maddern GJ. Systematic review of treatments for varicose veins. Ann Vasc Surg 2009; 23: 264-276.

15. Donnelly M, Tierney S, Feeley TM. Anatomical variation at the saphenofemoral junction. Br J Surg 2005; 92: 322-325. 